\title{
Granuloma Formation, a Rare Complication after PDO Threads Lifting, and Adjuvant Treatment Using Dual-Frequency Ultrasound (LDM ${ }^{\circledR}$-MED)
}

\author{
Seok Won Hong \\ Eun Soo Park
}

Department of Plastic \& Reconstructive Surgery, Soonchunhyang University Bucheon Hospital, Bucheon, Korea
Received June 26, 2019

Accepted June 27, 2019

\section{Correspondence}

Eun Soo Park

Department of Plastic and Reconstructive Surgery, Soonchunhyang University Bucheon Hospital, 1174 Jomaru-ro, Wonmi-gu, Bucheon 14584, Korea

Tel.: +82-32-621-5319

Fax: +82-32-621-5016

E-mail: peunsoodschmc.ac.kr

(C) Korean Society for Laser Medicine and Surgery

(c) This is an open access article distributed under the terms of the Creative Commons Attribution NonCommercial License (http://creativecommons.org/ licenses/by-nc/4.0) which permits unrestricted noncommercial use, distribution, and reproduction in any medium, provided the original work is properly cited.
Thread-lifting is a minimally invasive procedure that shows good results and fewer complications as compared with those results and complications of standard surgery. Many procedures and techniques have been developed to create a younger appearance of facial/neck skin for aging people, and the demand for an improved aesthetic appearance is increasing. Since the incidence of side effects is much less than that of non-absorbable threads, which can lead to complications such as foreign body reactions, polydioxanone (PDO) threads are predominantly used for face lift procedures. A 66-year-old woman presented to our clinic with inflamed palpable masses. She had undergone a face lift with absorbable threads in our clinic 5 months previously. Excisional biopsy was performed with the patient under local anesthesia. During the operation, any threads were not detected and there was both fibrotic scar tissue and granulomatous tissue. For effectively promoting healing and managing the scars, treatment with $\mathrm{LDM}^{\circledR}$-MED was performed on the day after surgery. The treatment was performed according to the author's protocol. Although foreign body granuloma as a complication after using non-absorbable thread types have been previously reported, it is relatively rare to find this type of complication after using absorbable thread. In this report, we present a case in which a 66-year-old female with foreign body granuloma after undergoing a face lift using absorbable threads was treated with the application of dual-frequency ultrasound, which promoted wound healing.

\section{Key words}

Granuloma; Threads lift; Ultrasound; Foreign body; Inflammation 


\section{INTRODUCTION}

Advancement in medicine and the increase of life expectancy have led to increased interests in the aging face. Many procedures and techniques have been developed to make younger than the ages or prevent the aging face as demand increases. More durable and less invasive procedures for face-lifts have been investigated to avoid invasive operation while retaining better results. In that sense, thread-lifting is as a minimally invasive technique for facial rejuvenation with minimized scaring and pain. ${ }^{1,2}$ It also has less complications compared with standard incisional surgery. ${ }^{3}$ Materials for thread-lift may be classified as absorbable or non-absorbable. For several decades, nonabsorbable polypropylene thread was favored for many physicians because of its durability. However, non-absorbable threads remain permanently in the tissue and result in complications such as inflammation and extrusion of sutures through the skin. ${ }^{4}$ Consequently, many physicians have preferred to using absorbable thread technique.

Although foreign body granuloma as complication after using non-absorbable thread types were reported, ${ }^{5}$ it is relatively rare to find after using absorbable thread. In this report, we present a case in which a 66-year-old female with foreign body granuloma after face lift using absorbable threads was treated with the application of dualfrequency ultrasound which provoke the wound healing. ${ }^{6}$

\section{CASE PRESENTATION}

A 66-year-old female presented to our clinic with her aging face and was performed the face lift using polydioxanone (PDO) threads named Cavern screw (Careis. INC, Korea) and $\mathrm{N} \operatorname{cog}(\mathrm{N}$-Finders INC, Korea). Each 2 and 6 threads of 27 and 29 gauge $50 \mathrm{~mm}$ sized needle type with $20 \mathrm{~mm}$ length Cavern screw were inserted at both lower eyedlid. 14 threads of 23
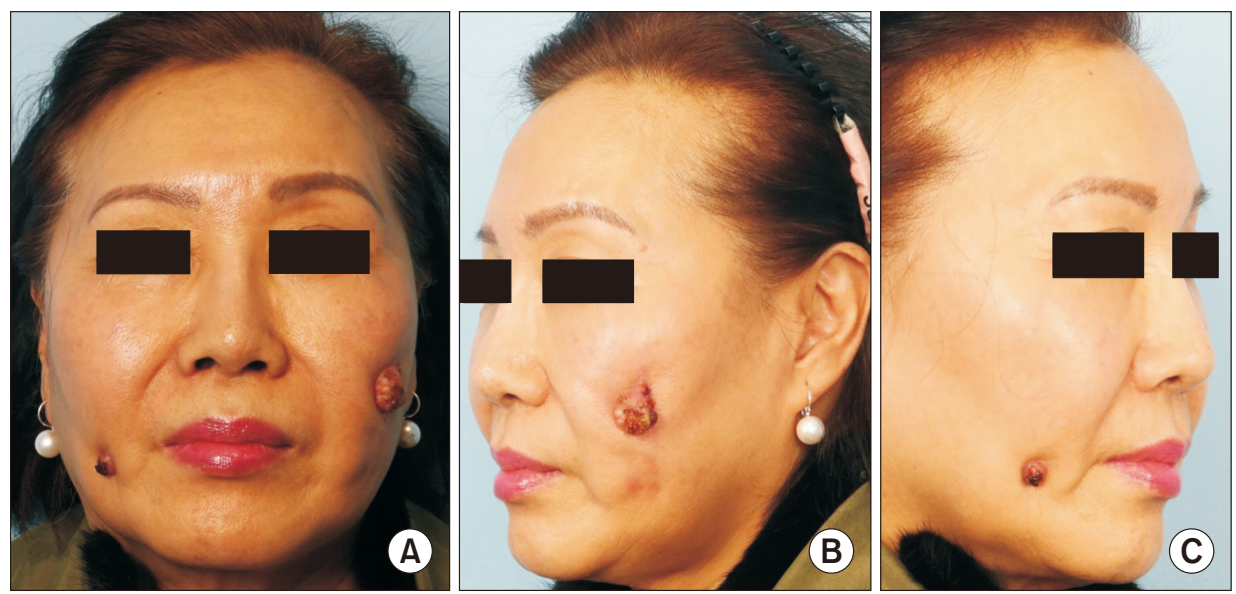

Fig. 1. Pre-operative images: Left sided mass was observed round shaped, $1.2 \times 1.3 \mathrm{~cm}$ sized pinkish color and right sided mass was observed round shaped, $0.4 \times 0.5 \mathrm{~cm}$ sized pinkish color. (A) Front view. (B) Left oblique view. (C) Right oblique view. gauge $60 \mathrm{~mm}$ sized needle type with $30 \mathrm{~mm}$ length Cavern screw were inserted at both midface and jowl. 12 threads of 21 gauge $60 \mathrm{~mm}$ sized needle type with $100 \mathrm{~mm}$ length $N$ cog were inserted at both lateral face and jowl for providind support. Face lift was performed effectively and there were no specific complications few months after the procedures. However, 5 months later, the patients presented to our clinic with protruding mass on her both cheek (Fig. 1). Left sided mass was observed round shaped, $1.2 \times 1.3 \mathrm{~cm}$ sized pinkish color and right sided mass was observed round shaped, $0.4 \times 0.5 \mathrm{~cm}$ sized pinkish color. She had not specific medical or traumatic history recently. Masses were excised and performed histopathologic examination under local anesthesia. During the operation, threads were not detect and there were fibrotic scarring tissue and granulomatous tissue. The histopathologic findings revealed foreign body granuloma with acute and chronic inflammation (Fig. 2). For controling foreign body reaction with chronic inflammation, the patient was also treated with per oral prednisolone $30 \mathrm{mg}$ for 3 weeks

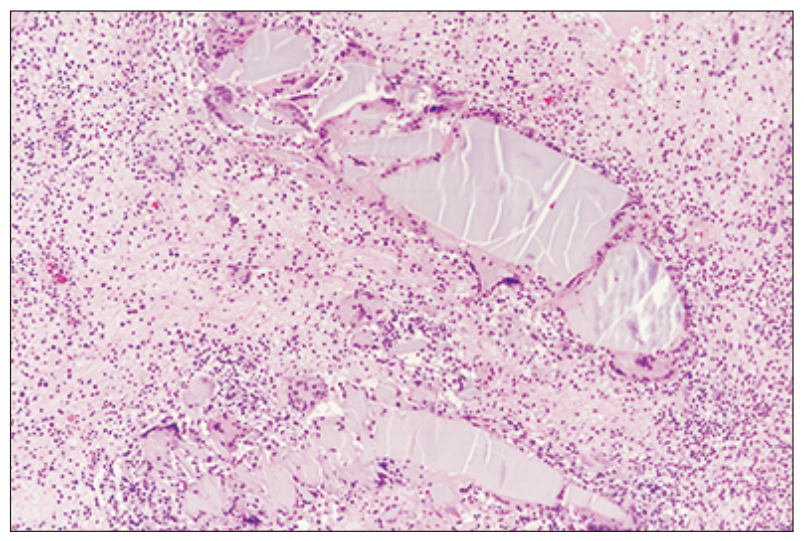

Fig. 2. Histopathologic images: It shows many foreign body giant cells near the amorphous bluish tan material, consistent with foreign body granuloma (Hematoxylin and Eosin stain, $\times 100$ ). 


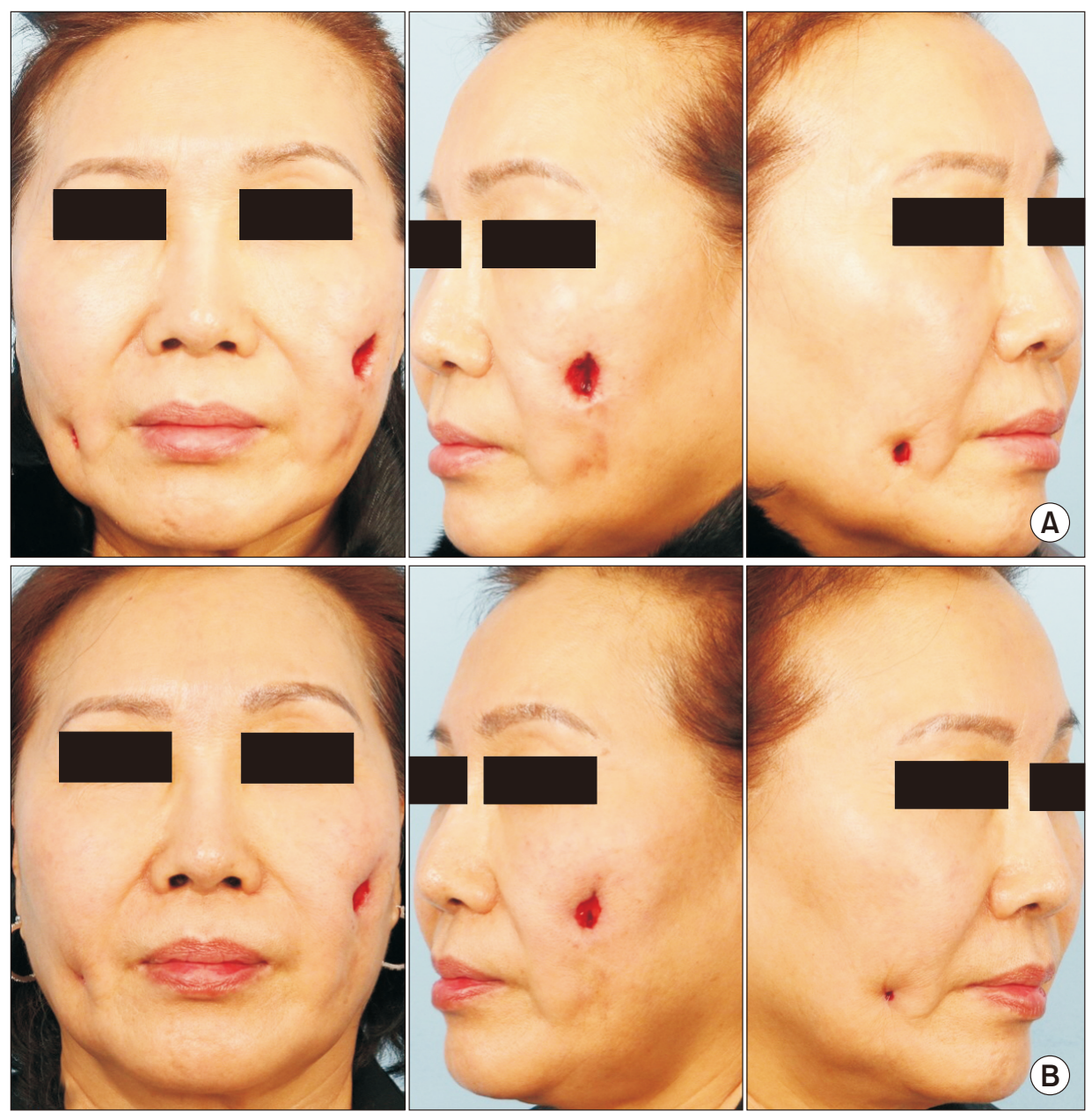

Fig. 3. Post-operative images: Mass was excised successfully and chronic inflammation and scarring tissue was found. (A) Immediate postoperative images. (B) Images after 5 sessions of application of $\mathrm{LDM}^{\circledR}$ MED.

as primary treatment and tapered by half every week. After the resection, the wound was not sutured because of chronic inflammation and scarring of surrounding tissue. Also, the patient does not want to make scar longer. For healing and managing scar effectively, treatment with LDM $^{\circledR}$-MED was performed from the day after surgery. Treatment was performed according to the author's protocol. The wound was at both side of face. It was each $1.5 \times 1.8 \mathrm{~cm}$ and $0.8 \times 0.8 \mathrm{~cm}$ sized without infection sign. She had a total of 11 sessions for a 2-week period. At each treatment session, the patient was evaluated by the author and clinical digital photographic documentation was carried out (Fig. 3). Treatment had been continued until the lesion was fully re-epithelized. The wound was totally healed with a few scars (Fig. 4).

\section{DISCUSSION}

Many procedures and techniques have been developed to make younger than the ages or prevent the aging face as demand increases. Since first invention of barbed suture by Sulamanidze in the late 1990s, the use of thread

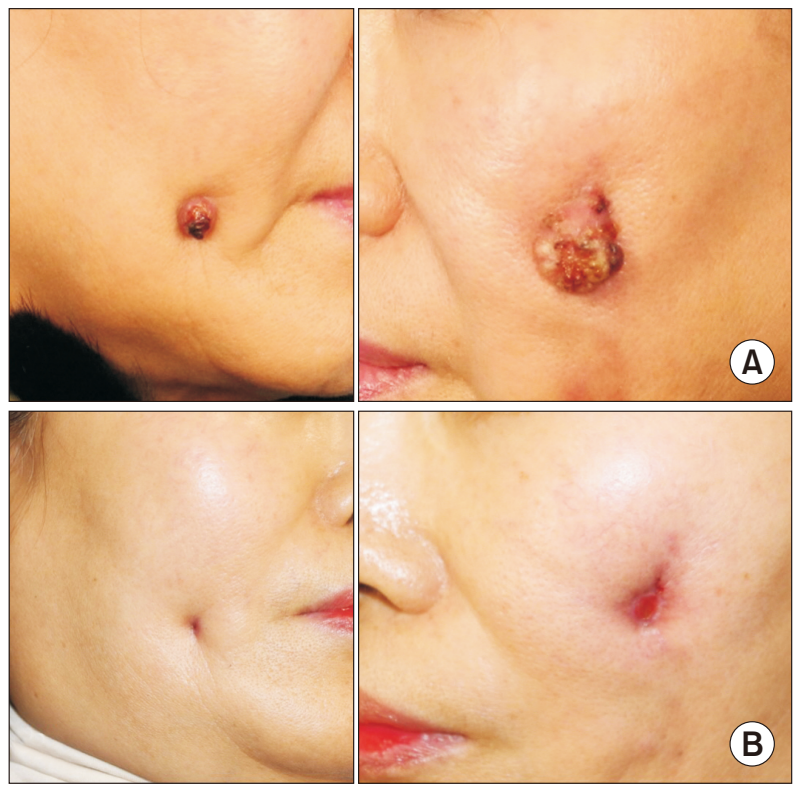

Fig. 4. Comparison between pre-operative images and post-recovery images. (A) Pre-operative images. (B) Images after all sessions of application of $\mathrm{LDM}^{\circledR}-\mathrm{MED}$. A few scar was observed and fully healed. 


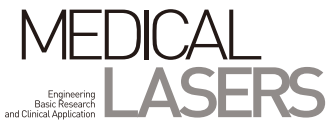

for face lifting has increased. Furthermore, due to the following advantages of thread lifts, patient's satisfaction is increasing and their preference is gradually increasing; Short recovery time, good result of face lifting, less pain and minimal scarring. 'Several kinds of thread including absorbable and non-absorbable have been developed and many studies are reported with effects and complications of thread lift. According to a report by Wu et al, ${ }^{7}$ patients experienced post-procedural side effects, including palpable threads with pain, thread migration, infections and granulomas. Other authors have also reported that patients who underwent pain, followed by dimpling, thread extrusion, paresthesia, and foreign body reactions. ${ }^{5}$

Since the incidence of side effects is much less than that of non-absorbable threads, which can lead to complications such as foreign body reactions, polydioxanone (PDO) threads are predominantly used for face lift. The sutures are completely absorbed over a period 4 to 6 months by the patient's immune system. Chronic inflammatory reactions caused by such absorbable threads are an infrequent complication in thread lifting. Some authors reported that repetitive trauma and micromovement between the barbs of the sutures and the surrounding capsule cause chronic inflammation in soft tissues of face., ${ }^{1,2}$

In our report, foreign body granuloma with chronic inflammation was occurred after face lift using PDO threads. This is a rare complication as mentioned above, we used dual-frequency ultrasound therapy to treat and manage effectively.

Recently, many studies have focused on the effectiveness and safety of dual-frequency ultrasound application for treating chronic wounds and inflammations. In 2011. Kruglikov and Kruglikova reported 10 cases of patients with chronic venous ulcer treated with dual-frequency ultrasound therapy (LDM) for 8-25 times. ${ }^{6}$ According to their study, new concepts of pathophysiology consisting in overexpression of matrix metallo-proteinases (MMPs) in the wound bed and under-expression of heat shock proteins (HSPs) in the wound were proposed. They reported that dual-frequency ultrasound (LDM) with frequencies of 3 and $10 \mathrm{MHz}$ based on simultaneous modulation of MMPs and HSPs in the wound seemed to be an effective alternative treatment for chronic wounds. All patients showed significant clinical outcomes. Chronic wounds became fully epithelized and pain level decreased at least 3 grades according to NRS scale. According to other report with Choi et al. ${ }^{8}$, venous ulcer was succefully treated with dual-frequency ultrasound therapy. When we consider all results of these studies with dual-frequency ultrasound therapy so far, this treatment is effective for healing of chronic wound.
The frequency of $L D M^{\circledR}-M E D$ is not constant. It oscilliates between two frequencies such as 3 and $10 \mathrm{MHz}$. A very rapid change of pressure gradients is thought to produce simultaneous modulation of MMPs and HSPs in the wound. ${ }^{6,8}$ Changing frequencies every $5 \mathrm{~ms}$ (200 times per second) is effective in decreasing MMPs and stimulating HSPs, thus helping the wound healing progress. In our case, we found intensive wound granulation after the second session of treatment. The patient's wound totally healed and epithelized at the end of the treatment. Because the treatment was pain free without side effects, the patient's satisfaction of the treatment was excellent.

Our results indicate that the application of $\mathrm{LDM}^{\circledR}$-MED seems to be a helpful treatment option for chronic inflammatory wound. Although our results are based on only one case and application of LDM ${ }^{\circledR}$-MED was for adjuvant treatment with primary systemic steroid therapy, it is expected to be therapeutic benefit in patients with chronic wounds with our LDM ${ }^{\circledR}$-MED protocol.

\section{CONFLICT OF INTEREST}

The authors report no conflicts of interest.

\section{REFERENCES}

1. Sulamanidze M, Sulamanidze G, Vozdvizhensky I, Sulamanidze C. Avoiding complications with Aptos sutures. Aesthet Surg J 2011;31:863-73.

2. Kaminer MS, Mandy S. ContourLift ${ }^{\mathrm{TM}}$ : a new method of minimally invasive facial rejuvenation. Cosmet Dermatol 2007;20:29-35.

3. Villa MT, White LE, Alam M, Yoo SS, Walton RL. Barbed sutures: a review of the literature. Plast Reconstr Surg 2008;121:102e-8e.

4. Isse NG, Fodor PB. Elevating the midface with barbed polypropylene sutures. Aesthet Surg J 2005;25:301-3.

5. Rachel JD, Lack EB, Larson B. Incidence of complications and early recurrence in 29 patients after facial rejuvenation with barbed suture lifting. Dermatol Surg 2010;36:348-54.

6. Kruglikov I, Kruglikova E. Dual treatment strategy by venous ulcers: pilot study to dual-frequency ultrasound application. J Cosmet Dermatol Sci Appl 2011;1:157-63.

7. Wu WT. Barbed sutures in facial rejuvenation. Aesthet Surg J 2004;24:582-7.

8. Choi YS, Nam SM, Park ES. Clinical experience of effective treatment of intractable chronic venous ulcer using LDM. Med Lasers 2017;6:29-31.

9. McMurtry AL, Cho K, Young LJ, Nelson CF, Greenhalgh DG. Expression of HSP70 in healing wounds of diabetic and nondiabetic mice. J Surg Res 1999;86:36-41. 